Original Research Paper

\title{
Investigation on the Performance of Producer Gas Fired Reversible Flat-Bed Dryer
}

\author{
${ }^{1}$ W. Beno Wincy, ${ }^{2}$ M. Edwin and ${ }^{3}$ S. Joseph Sekhar \\ ${ }^{1,2}$ Department of Mechanical Engineering, University College of Engineering, \\ Nagercoil, Anna University Constituent College, Nagercoil, Tamil Nadu, India \\ ${ }^{3}$ Department of Mechanical Engineering, Shinas College of Technology, Sultanate of Oman
}

\author{
Article history \\ Received: 29-08-2019 \\ Revised: 02-09-2019 \\ Accepted: 11-09-2019 \\ Corresponding Author: \\ Edwin M. \\ Department of Mechanical \\ Engineering, University \\ College of Engineering, \\ Nagercoil, Anna University \\ Constituent College, Nagercoil, \\ Tamil Nadu, India \\ Email: edwinme1980@gmail.com
}

\begin{abstract}
Rice is one of the important crops which supplies energy to around $80 \%$ of the world population. Paddy drying is an energy intensive process as huge amount of energy is required for drying. Direct combustion of rice husk or wood is followed at the mills to generate heat which is found to be less efficient and highly environment polluting. Hence it is necessary to adopt an energy efficient and environment friendly equipment for drying parboiled paddy. This paper presents a new method of paddy drying in a reversible flat-bed dryer using producer gas as fuel from rice husk gasification. The drying experiment was conducted with the parboiled paddy at the temperature of $70^{\circ} \mathrm{C}$ for $6.5 \mathrm{~h}$ to reduce the moisture content from $38.4 \%$ to $14 \%$. The energy usage during the drying operation is in the range of $0.9-0.09 \mathrm{~kJ} / \mathrm{s}$. The overall system efficiency of the gasifier operated reversible flat-bed dryer and the reversible flat-bed dryer are $50.75 \%$ and $38.08 \%$ respectively.
\end{abstract}

Keywords: Reversible Flat-Bed Dryer, Parboiled Paddy, Drying, Producer Gas, Rice Husk

\section{Introduction}

Drying is an important process in preserving the food products. Paddy after parboiling is dried to the desired moisture content for safe storage and to prolong its life. Hiler and Stout (1985) reported that drying process is found to be energy intensive as it requires huge amount of energy to remove moisture by evaporation. Garg and Prakash (1997) stated that open sun drying is the common method for drying the agricultural products. It is found to be economic as it consumes energy for free of cost and it does not requires large machineries. The sun drying process possess disadvantages like less product quality, dust contaminants, labor intensive, consumes huge time and also climatic dependent (Basunia and Abe, 2001; Panwar et al., 2012). Lalit (1990) recommended that to reduce the time consumption and increase the product quality, biomass is used to generate the required heat for drying through direct combustion method.

The drying is carried out either by direct or indirect method. Sukup et al. (1982) mentioned that hot flue gas after the combustion process is used as the drying medium in the direct drying method whereas in the indirect method the heat is transferred from the hot flue gas to the secondary air through heat exchanger to dry the product. It is found that $45-64 \%$ of the energy from the biomass is used to heat the drying air in the indirect method of drying (Sumner et al., 1981). Mwaura et al. (1983) reported that the direct method of drying has more efficiency when compared with indirect method whereas the contaminant from the flue gas directly contacts the paddy surface which reduces the quality of the product is the only issue. It is reported that the drying of copra was carried out at $50-55^{\circ} \mathrm{C}$ in the direct dryer type using coconut shell as fuel which has the thermal efficiency of 26\% (Sachidananda et al., 2014).

Dhanushkodi et al. (2015) stated that a cashew nut dryer using wood as fuel and around the drying temperature maintained at $70-75^{\circ} \mathrm{C}$ has the system efficiency of only 16\%. Prasad et al. (2006) reported that the solar cum biomass hybrid dryer which was used in drying of turmeric possess the overall efficiency of $28.57 \%$. Hamdani et al. (2018) developed and investigated a hybrid dryer to reduce the usage of biomass fuels and to improve the system efficiency. A hybrid solar-biomass dryer for fish drying was investigated in which wood is used as fuel 
and the temperature of $40-50^{\circ} \mathrm{C}$ was maintained. It was found to more advantage in efficiency and economical than the biomass fired dryer.

The usage of biomass through direct combustion was found to more dangerous to environment and human health because of the generation of toxic components like CO, SOx, NOx etc,. Hence researchers concentrated to alter or retrofit the existing system to improve the efficiency and reduce the fuel demand. Biomass gasifier is one of the promising techniques to reduce the above-mentioned drawbacks. Beno et al. (2018) reported that biomass gasifiers have the advantages of fuel flexibility like fuel type, size, density, calorific value and moisture content. It is reported that downdraft biomass gasifier of efficiency $84.97 \%$ was used for drying palm oil fruit bunch at the temperature of $150-180^{\circ} \mathrm{C}$ using wood residues as the feed stock (Woranuch, 2017). Rathore et al. (2008) mentioned that gasification which is used in dryer for increasing the concentration of the phosphoric acid at the temperature of 690 $740^{\circ} \mathrm{C}$ has the efficiency of $68 \%$. Burning of producer gas using a burner generates flame of temperature $1200^{\circ} \mathrm{C}$ with the thermal efficiency of $91 \%$ (Punnarapong et al., 2017). The convective heat exchanger which transfers heat from hot flue gas from producer gas burning to the air through walls has the effectiveness of $62.5 \%$ (Al-attab and Zainal, 2010).

From the literature survey it is found that, there is no literature based the reversible flat-bed dryer operated with the producer gas from biomass gasification for parboiled paddy drying. Hence this gap paved the way to fabricate and investigate the performance of producer gas fired reversible flat-bed dryer for parboiled paddy drying and the performance parameters such as energy used, specific fuel consumption and overall system efficiency is studied.

\section{Materials and Methods}

\section{Design Procedure for Reversible Flat-Bed Dryer}

The reversible flat-bed dryer was designed to dry 30 $\mathrm{kg}$ paddy. The density of the paddy varies between $450-$ $650 \mathrm{~kg} / \mathrm{m}^{3}$. The heat supplied into the dryer is utilized in three forms i.e., the sensible heat gained by the grain, sensible heat gained by the moisture content and the heat gained to convert moisture to water vapor.

Heat gained to rise the paddy temperature i.e., sensible heat of paddy $\left(Q_{p}\right)$ is calculated from:

$\mathrm{Q}_{p}=W_{p} \times C_{p} \times \Delta T$

Where:

$W_{p}=$ The bone dry weight of paddy $(\mathrm{kg})$.
$C_{p}=$ The specific heat of paddy $(\mathrm{kJ} / \mathrm{kg} \mathrm{K})$

$\Delta T=$ The temperature difference

The bone dry weight of paddy $\left(W_{p}\right)$ can be calculated form the following relation:

$W_{p}=m_{p} \times\left(1-M C_{f}\right)$

Where:

$m_{p}=$ The mass of paddy $(\mathrm{kg})$

$M C_{f}=$ The final moisture content of paddy (\%)

Heat gained to rise the temperature of moisture content (sensible heat of water) is calculated from:

$\mathrm{Q}_{p}=W_{p} \times M C_{i} \times C_{w} \times \Delta T$

Where:

$M C_{i}=$ The initial moisture content of paddy $(\%)$

$C_{w}=$ The specific heat of water $(\mathrm{kJ} / \mathrm{kg} \mathrm{K})$

Amount of moisture $\left(W_{m}\right)$ to be removed can be found from the following relation:

$W_{m}=W_{p} \times\left(M C_{i}-M C_{f}\right)$

Heat gained to convert the moisture content into water vapour $\left(h_{\text {vap }}\right)$ is calculated from:

$h_{\text {vap }}=W_{m} \times 2256$

Where:

$W_{m}=$ The moisture to be removed $(\mathrm{kg})$

Humid heat of air $(\mathrm{Z})$ is found from:

$Z=0.24+(0.45 \times H)$

If, $t$ is the time of drying then the heat to be supplied (Q) can be found from the following relation:

$Q=\dot{m}_{a} \times Z \times\left(T_{2}-T_{1}\right) \times t$

Where:

$t=$ The drying time $(\mathrm{sec})$.

The total heat to be supplied is given by:

$Q=Q_{p}+Q_{w}+h_{v a p}$

Therefore from Equation 7 and 8, the mass flow rate of air $\left(m_{a}\right)$ required can be determined. Volume flow rate of air $\left(v_{a}\right)$ can be found from: 
$\dot{v}_{a}=\dot{m}_{a} / x$

Where:

$x=$ The humid volume of ambient air $\left(\mathrm{m}^{3} / \mathrm{kg}\right)$.

Normally, the area perforated in the bed is considered as $50 \%$ of the total bed surface. Therefore, the area through which the air passes is given by:

Air requirement per $\mathrm{m}^{2}=\dot{v}_{a} /(\mathrm{l} \times b \times 0.50)$

Where:

$l=$ The length of drying bed (m)

$b=$ The breadth of drying bed $(\mathrm{m})$

From Shedd's curve, the static pressure drop near to air requirement per $\mathrm{m}^{2}$ can be found and it can be used to find the pressure drop in terms of air column in meter from the following relation:

$\Delta P=$ static pressure drop per $c m \times h \times 10 / \rho_{a}$

$\rho_{a}$ is the density of air $\left(\mathrm{kg} / \mathrm{m}^{3}\right)$.

Capacity of blower can be found from:

$H_{p}=\frac{\Delta P \times \dot{m}_{a}}{4500}$

The capacity of the burner can be found by dividing the total heat required to dry the paddy $(\mathrm{Q})$ to the time $(\mathrm{t})$ of paddy drying and it is given by the following relation:

$B=Q / t$

\section{Theoretical Analysis of Producer Gas Fired Reversible Flat-Bed System}

The moisture content at any time during the drying process can be calculated from the following relation:

$M_{i}=\frac{W_{0}\left(M C_{i}-1\right)+W}{W}$

Where:

$W_{0}=$ The initial weight of sample $(\mathrm{kg})$

$W=$ The weight of sample at a time $(\mathrm{kg})$

The energy utilized (EU) during the drying process was calculated from the following equation:

$$
E U=m_{d a}\left(h_{i a}-h_{o a}\right)
$$

Where:

$h_{a i}=$ The enthalpy of inlet air $(\mathrm{kJ} / \mathrm{kg})$

$h_{o a}=$ The enthalpy of exit air $(\mathrm{kJ} / \mathrm{kg})$

$m_{d a}=$ The mass of drying air $(\mathrm{kg})$
The specific fuel consumption and producer gas consumption was calculated from the equations (16) and (17) respectively:

$$
S F C=\frac{\dot{E}_{p g} \times t \times 3600}{C V_{r h} \times m_{p} \times 1000}
$$

$S P G C=S F C \times 2.2$

Where:

$C V_{r h}=$ The calorific value of rice husk $(\mathrm{kJ} / \mathrm{kg})$

$E_{p g}=$ The energy flow rate $(\mathrm{kJ} / \mathrm{s})$

The efficiency of the reversible flat-bed dryer was calculated from the following equation:

$\eta_{d}=\frac{\dot{m}_{a}\left(h_{i a}-h_{o a}\right)}{\dot{m}_{a}\left(h_{i a}-h_{a a}\right)}$

Where:

$h_{a a}=$ The enthalpy of ambient air $(\mathrm{kJ} / \mathrm{kg})$

The overall system efficiency of producer gas fired reversible flat-bed system was calculated from the following relation:

$\eta_{o}=\frac{\text { Heat utilized for removing the water }}{\text { Total heat supplied }}$

\section{Experimental Procedure}

The schematic diagram of the experimental setup is shown on Fig. 1. The soaked paddy is to be loaded into the dryer such that the thermocouples T3, T4 and T5 are in the upper, middle and lower portion of the drying bed. The producer gas which is generated from the biomass through gasifier is used to heat the bottom surface of the heat exchanger using a burner. Air is blown into the heat exchanger by the blower which is regulated by the valves $\mathrm{V} 1$ and $\mathrm{V} 2$ to carry the heat generated at the heat exchanger.

Initially the hot air is allowed to enter into the lower plenum chamber by opening the valve V4 where the valve V3 remains closed and the upper exit must be open. The air passes through the drying bed from bottom to top direction for $15 \mathrm{~min}$ in which the lower layer of the drying material gets dried up. After $30 \mathrm{~min}$, the direction of hot air is reversed by opening the valve V3 and shutting the valve V4. In that time, the upper exit must be closed and the lower exit must be open. Now the hot air crosses the drying bed from top to bottom direction. This heats the upper layer of the bed and dries the paddy from the upper layer to the lower layer. The direction of the hot air flow inside the dryer was exchanged till the drying process gets over. 


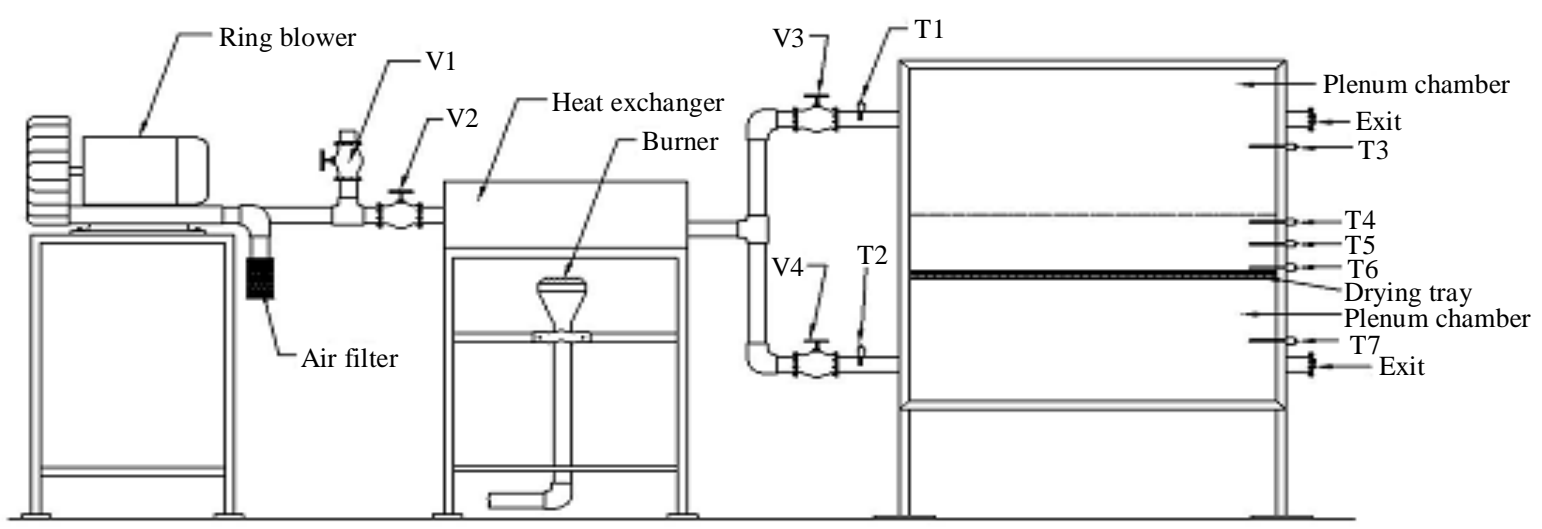

Fig. 1: Schematic diagram of the producer gas fired reversible flat-bed dryer

Table 1: Details of experimental device and instrument

\begin{tabular}{lll}
\hline Instrument & Capacity & Make \\
\hline Downdraft gasifier & $40 \mathrm{~kW}$ & Ankur \\
Reversible flat-bed dryer & $30 \mathrm{~kg}$ & - \\
Ring blower & $1 \phi, 0.7 \mathrm{~kW}, 5 \mathrm{~A}, 145 \mathrm{~m} 3 \mathrm{~h}-1$ & Cleantek \\
Thermocouple & $\leq 1000^{\circ} \mathrm{C}$ & Chandi Electricals \\
Temperature indicator & upto $1000^{\circ} \mathrm{C}($ K-type $)$ & Chandi Electricals \\
Stove burner & $4 \mathrm{~kW}$ & Sri Jothi Modern Kitchen Equipment \\
\hline
\end{tabular}

The samples have to be taken out and weighed in regular interval of time to find the moisture loss in the paddy. The drying process gets over when the paddy reaches the required moisture content. The temperature inside the dryer has to be monitored so as to have a uniform temperature for drying process. The details of the experimental device and instrument are given in Table 1.

\section{Results and Discussion}

In this study a reversible flat-bed dryer was developed for processing $30 \mathrm{~kg}$ of parboiled paddy as per the procedure discussed in section 2.1 to have less energy consumption, investment cost and environmental effect. The experiment was conducted at the drying air temperature of $70^{\circ} \mathrm{C}$ and the observation were made for evaluating the performance of the system and the same are discussed below.

The experiment was conducted to reduce the moisture content of the parboiled paddy from $38.4 \%$ to $14 \%$ at the drying temperature of $70^{\circ} \mathrm{C}$ for $6.5 \mathrm{~h}$. The volumetric air flow rate was maintained at 0.019 $\mathrm{m}^{3} / \mathrm{s}$. The variation of moisture content and weight loss of parboiled paddy sample during the drying process is given in Fig. 2. It shows the weight of the paddy sample gradually decreases with the increase in the drying temperature. It is due to the steady removal of water molecules from the soaked paddy by the incoming hot drying air. The removal of water particles from the parboiled considerably reduces its moisture content from 38.4 to $14 \%$ in $6.5 \mathrm{~h}$.
As the temperature of the paddy during drying process influence the quality of rice, the temperature of the parboiled paddy at different position in the drying bed was also recorded during the drying process. Figure 3 shows the variation of upper, middle and lower bed temperature of parboiled paddy during drying process. It shows that upper, middle and lower bed temperature increases with the increase in drying time and reaches the maximum temperature of $62.5^{\circ} \mathrm{C}$, $57^{\circ} \mathrm{C}$ and $52^{\circ} \mathrm{C}$ respectively. It also shows that temperature of the parboiled paddy in the upper and middle layer is greater than the lower layer. The direct exposure of parboiled paddy with the incoming drying air heats up the parboiled paddy in the upper and middle layer whereas the temperature of lower layer of parboiled paddy is slowly increased. This slow rise in temperature of lower layer paddy is due to the absorption of heat energy by the bottom perforated metal sheet. And hence there is a temperature gradient of $10^{\circ} \mathrm{C}$ in upper and lower layer at the end of drying process.

The variation of energy usage with respect to drying time is shown in Fig. 4. It shows that the energy usage in drying of parboiled paddy decreases with increase in drying time. The drying air of $70^{\circ} \mathrm{C}$ has the relative humidity of about $10 \%$. At the initial stage of drying, the temperature of the exit $\left(35^{\circ} \mathrm{C}\right)$ is very low than the inlet drying temperature. The initial low temperature of the exit air possesses high relative humidity of $85 \%$. It indicates that the heat energy in the drying air is highly absorbed by the water molecules in the parboiled paddy and gets transformed to water vapour. 


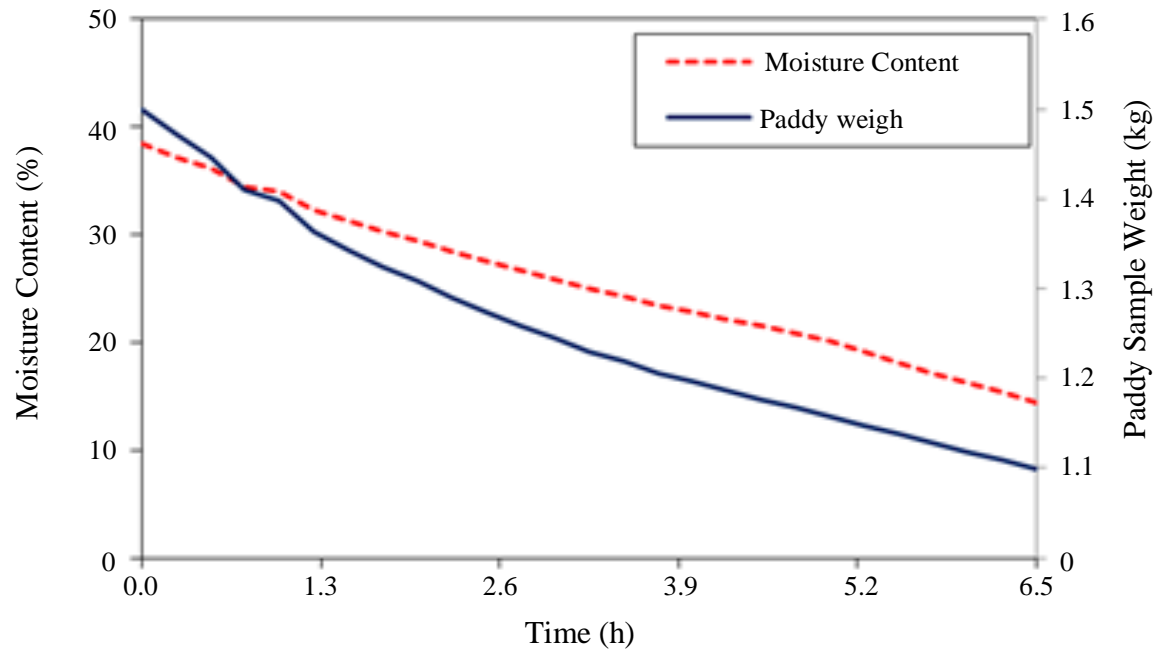

Fig. 2: Variation of moisture content and sample weight of parboiled paddy

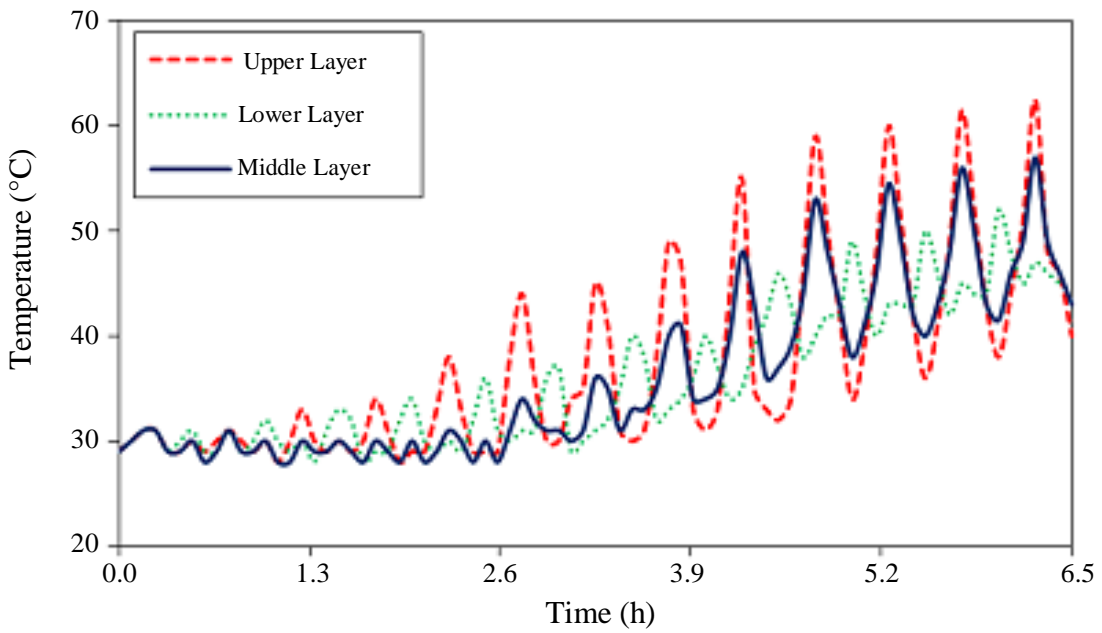

Fig. 3: Variation of drying bed temperature during drying process

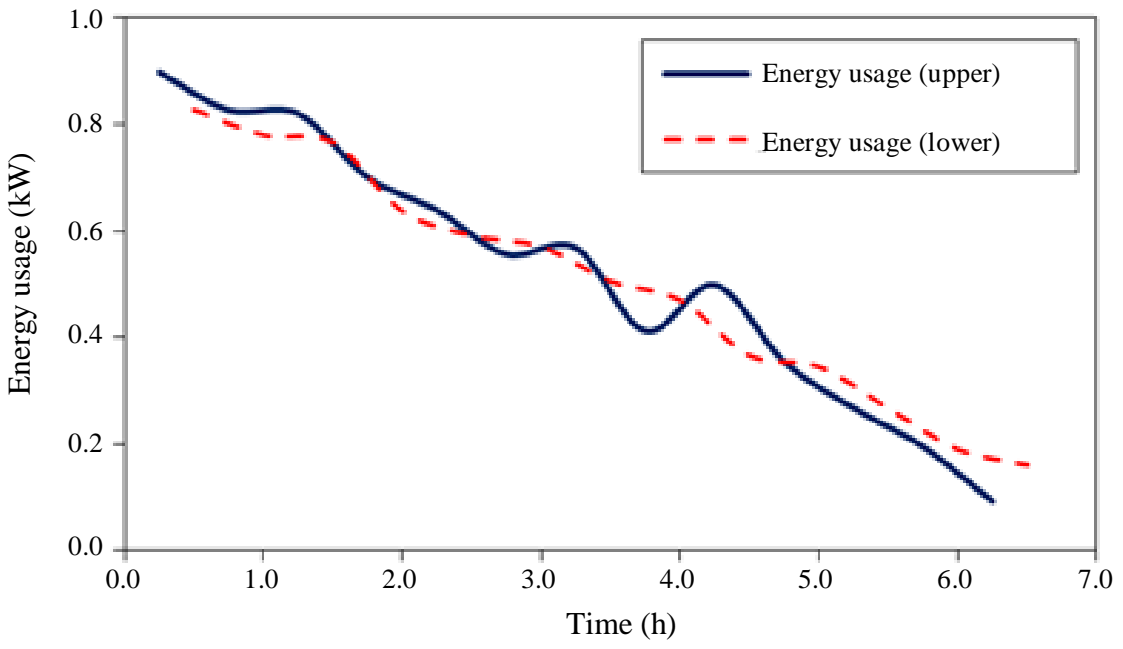

Fig. 4: Variation of energy usage by paddy with respect to drying time 


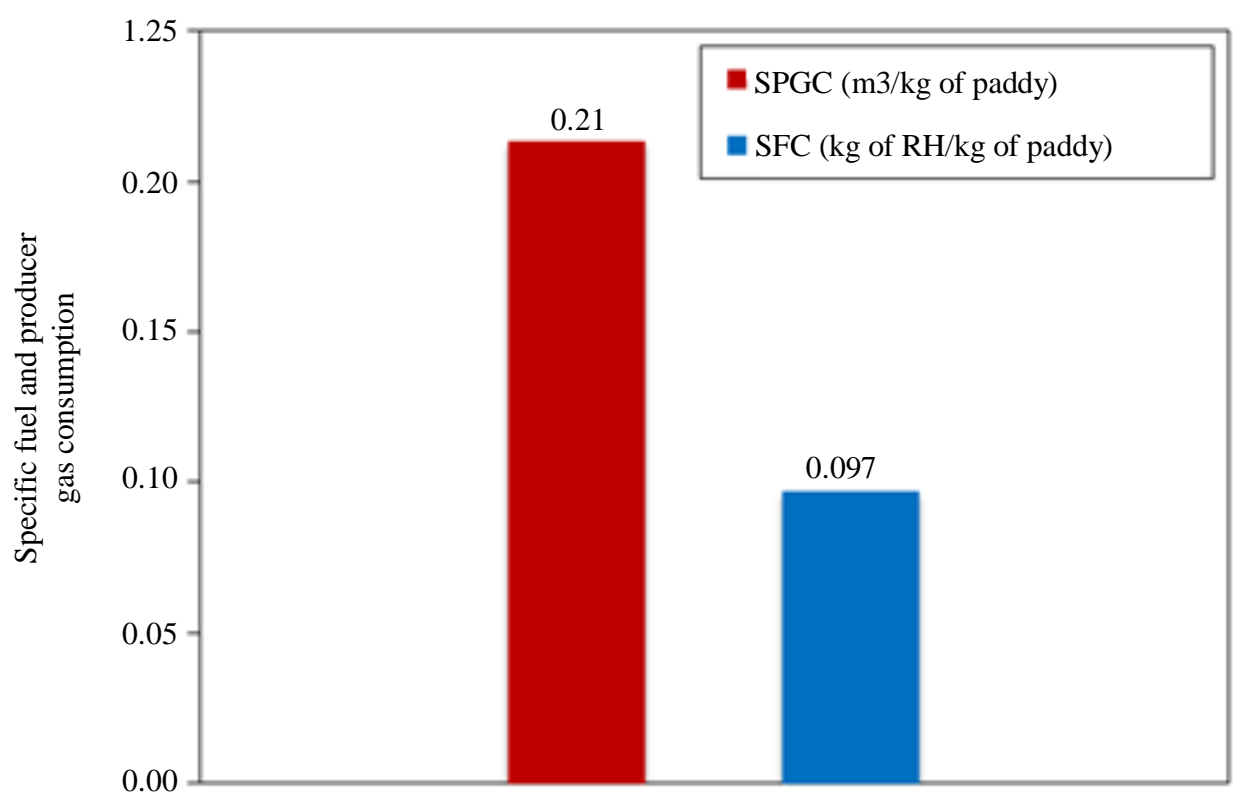

Fig. 5: Specific producer gas and fuel consumption in producer gas fired reversible flat-bed dryer

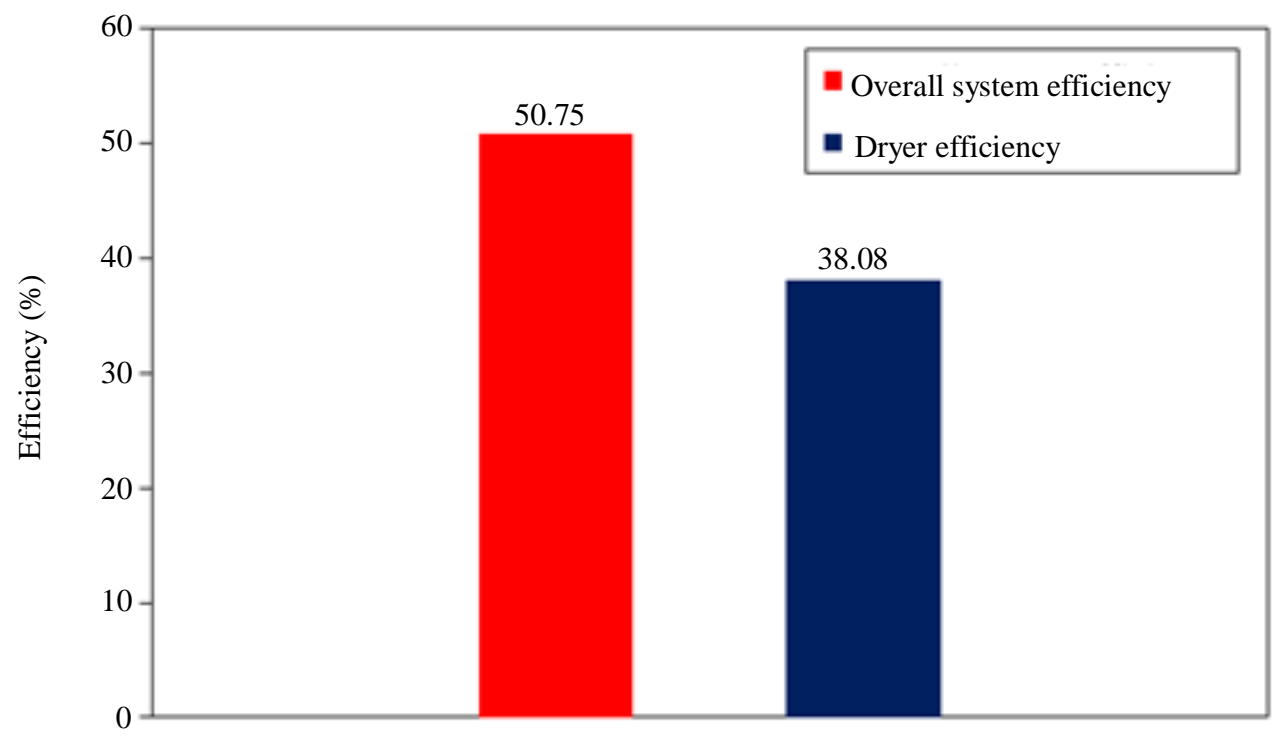

Fig. 6: Overall system and dryer efficiency

This vapour increases the humidity of air and lowers drying air temperature. When the experiment proceeds, moisture removal rate is decreased and hence the heat absorption by the paddy is also decreased. This decreases the energy usage of the incoming air and leaves the air at higher temperature of $65^{\circ} \mathrm{C}$ with less relative humidity of $20 \%$.

The fuel supplied to the gasifier and producer gas supplied to the burner was measured during the experiment. The specific fuel and producer gas consumption for drying paddy is estimated and are shown in Fig. 5. It shows that, drying of the parboiled paddy in a producer gas fired reversible flat-bed dryer has the specific produce gas and fuel consumption of 0.21 $\mathrm{Nm}^{3} / \mathrm{kg}$ and $0.097 \mathrm{~kg} / \mathrm{kg}$ of paddy respectively. The specific consumption of rice husk in drying paddy using this system is considerably low when compared with the other paddy drying systems. This may be due to the effective utilization of rice husk in the energy conversion process and the heat in the reversible flat-bed dryer. 
The overall system efficiency and the dryer efficiency are shown in Fig. 6. It shows the overall efficiency of the producer gas fired reversible flat-bed dryer and the reversible flat-bed dryer are $50.75 \%$ and $38.08 \%$ respectively. The overall system efficiency is also found to be better than the other paddy drying system which may be due to the less consumption of rice husk by the effective utilization of gasification process. Thus increase in overall system efficiency reduces then environment effect.

\section{Conclusion}

Paddy drying is one of the important steps in rice processing. Biomass fuel is the economically viable one when compared with the conventional fuels. The serious effects in the burning of biomass fuels are the energy issues and the environmental impact. The producer gas from the biomass is the better alternative fuel to supply the required heat energy with minimal environmental effect. The experimental results shows that the energy usage during the drying operation is in the range of $0.9-0.09 \mathrm{~kJ} / \mathrm{s}$. The overall system efficiency of the gasifier operated reversible flat-bed dryer and the reversible flat-bed dryer are $50.75 \%$ and $38.08 \%$ respectively. This type of dryer can be commercially established as it has advantages like less energy consumption, pollution free and are economic.

\section{Author's Contributions}

W. Beno Wincy: Participated in all experiments, coordinated the data-analysis and contributed to the writing of the manuscript.

M. Edwin: Designed the research plan and organized the study, Contributed to the writing of the manuscript.

S. Joseph Sekhar: Mentoring the research and contributed to the writing of the manuscript.

\section{Ethics}

This article is original and contains unpublished material. The corresponding author confirms that all of the other authors have read and approved the manuscript and no ethical issues involved.

\section{References}

Al-Attab, K.A. and Z.A. Zainal, 2010. Performance of high temperature heat exchangers in biomass fuel powered externally fired gas turbine systems. Renewable Energy, 35: 913-920. DOI: 10.1016/j.renene.2009.11.038

Basunia, M.A. and T. Abe, 2001. Thin-layer solar drying characteristics of rough rice under natural convection. J. Food Engineering, 47: 295-301. DOI: $10.1016 / \mathrm{S} 0260-8774(00) 00133-3$
Beno, W., W.M. Edwin, V. Christus Jeya Singh and S. Joseph Sekhar, 2018. Design and analysis of a bubbling fluidized bed gasifier using different biomasses. Proceedings of International Conference on Energy Efficient Technologies for Sustainability, St. Xavier's Catholic College of Engineering, Tamil Nadu, India. April 5-7.

Dhanushkodi, S., H. Vincent Wilson and K. Sudhakar, 2015. Design and performance evaluation of biomass dryer for cashew nut processing. Advances Applied Sci. Res., 6: 101-111.

Garg, H.P. and J. Prakash, 1997. Solar energyfundamentals and applications. Tata McGraw-Hill Publishing Company Ltd.

Hamdani, T., A. Rizal and Z. Muhammad, 2018. Fabrication and testing of hybrid solar-biomass dryer for drying fish. Case Studies Thermal Engineering, 12: 489-496.

DOI: $10.1016 /$ j.csite.2018.06.008

Hiler, E.A. and B.A. Stout, 1985. Biomass Energy, A Monograph. TEES Monograph Series, Texas A \& M University Press.

Lalit, V.R., 1990. Biomass Energy for rice drying. Biomass, 23: 13-23.

DOI: 10.1016/0144-4565(90)90070-Z

Mwaura, E.N., F.W. Bakker-Arkema, G.R. Van Ee and W.E. Braselton, 1983. Grain contamination in drying by direct biomass heating. ASAE Paper No. 83-3512. American Society of Agricultural Engineers, St Joseph, MI.

Panwar, N.L., S.C. Kaushik and S. Kothari, 2012. State of the art of solar cooking: an overview. Renewable and Sustainable Energy Rev., 16: 3776-3785. DOI: $10.1016 /$ j.rser.2012.03.026

Prasad, J., V.K. Vijay, G.N. Tiwari and V.P.S. Sorayan, 2006. Study on performance evaluation of hybrid drier for turmeric (Curcuma longa L.) drying at village scale. J. Food Eng., 75: 497-502.

DOI: 10.1016/j.jfoodeng.2005.04.061

Punnarapong, P., T. Sucharitakul and N. Tippayawong, 2017. Performance evaluation of premixed burner fueled with biomass derived producer gas. Case Studies Thermal Engineering, 9: 40-46. DOI: $10.1016 /$ j.csite.2016.12.001

Rathore, N.S., N.L. Panwar and Y. Vijay Chiplunkar, 2008. Industrial application of biomass based gasification system. World Applied Sci. J., 5: 406-409.

Sachidananda, S., M. Din, R. Chandrika, G.P. Sahoo and S.D. Roy, 2014. Performance evaluation of biomass fired dryer for copra drying: A comparison with traditional drying in subtropical climate. J. Food Processing Technology, 5: 294-299. DOI: 0.4172/2157-7110.1000294 
W. Beno Wincy et al. / Energy Research Journal 2019, Volume 10: 48.55 DOI: 10.3844/erjsp.2019.48.55

Sukup, C. E., C.J. Bern and W.E. Buchele, 1982 Performance of a biomass furnace for grain drying. ASAE Paper No. 82-3524. American Society of Agricultural Engineers, St Joseph, M1.

Sumner, H.R., R.E. Sumner, C.W. Hammond and G.E. Monroe, 1981. Energy available from biomass for grain drying. ASAE Paper No. 81-3014. American Society of Agricultural Engineers, St Joseph, MI.
Woranuch, J., 2017. Utilization of biomass gasifier system for drying applications. Energy Procedia, 138: $1041-1047$.

DOI: 10.1016/j.egypro.2017.10.097 